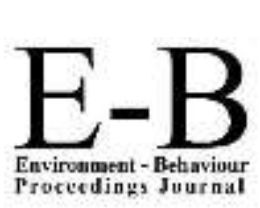

\author{
CSSR2019 \\ 6th International Conference on Science \& Social Research 2019 \\ https://cssr.uitm.edu.my/2019/ \\ Parkroyal Penang Resort, Batu Ferringhi, Pulau Pinang, Malaysia, 04-05 Dec 2019
}

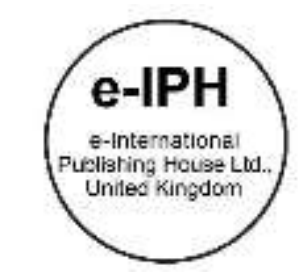

\title{
Proactivity Among Academicians In Malaysian Private Universities
}

\author{
Cheah Chew Sze1, Tan Cheng Ling², Yeo Sook Fern ${ }^{3}$ \\ 1,3 Multimedia University, Jalan Ayer Keroh Lama, Melaka 75450, Malaysia \\ 2 Universiti Sains Malaysia, Gelugor, Penang 11800, Malaysia \\ cheah.chew.sze@mmu.edu.my, tanchengling@usm.my, yeo.sook.fern@mmu.edu.my \\ Tel of 1 st Author: +60178800263
}

\begin{abstract}
The study examines demographic variables' role in academicians' proactive work behaviour (PWB) in private universities. Independent sample t-test and one-way Analysis of Variance (ANOVA) were performed using self-reported data from 287 academicians. Results show that academicians demonstrated moderate proactivity level. Male demonstrate higher proactiveness compared to females. Married workers score higher on PWB. An academician who holds a managerial position tends to be more proactive compared to others. Furthermore, Doctor of Philosophy (PhD) holder displays a higher level of productivity. The findings offer practical suggestions to the university to address the situation and delegate job assignments based on individual differences.
\end{abstract}

Keywords: proactive work behaviour; academicians; demographic variables; private university

eISSN: 2398-4287@ 2021. The Authors. Published for AMER ABRA cE-Bs by e-International Publishing House, Ltd., UK. This is an open access article under the CC BYNC-ND license (http://creativecommons.org/licenses/by-nc-nd/4.0/). Peer-review under responsibility of AMER (Association of Malaysian Environment-Behaviour Researchers), ABRA (Association of Behavioural Researchers on Asians/Africans/Arabians) and cE-Bs (Centre for Environment-Behaviour Studies), Faculty of Architecture, Planning \& Surveying, Universiti Teknologi MARA, Malaysia.

DOI: https://doi.org/10.21834/ebpj.v6iSI4.2907

\subsection{Introduction}

The educational institution is considered a service industry that plays an important role in creating the intelligent, well-educated, firstclass human capital mindset needed in this era. The massive growth in Malaysia's higher education over the past two decades has helped put Malaysia on the global playing field by offering higher education to an increasing number of Malaysian and international students. Quality education can only be achieved with excellent teachers. One of the key measures of a high-quality education institution is its academic staff's qualifications and research capacity. In this case, academic staff have a vital role in maintaining the quality of education as they have served as the basis for any progress in higher education institutions.

In reality, do the academicians in private universities proactive in their work? Hashim (2012) pointed out that academicians in private universities lack creativity, with a "work for living" attitude only and no self-initiating. While looking into the outcome of initiating innovation among the academicians in private Higher Education Institutions (HEls), the research performance analysis of both public and private HEls in Malaysia using the data from Web of Science (WOS) and SCOPUS databases (from the year 2014-2017) showed, very few of private HEls have been able to list in the top 10 of total citations in WOS and SCOPUS databases if compared with public HEls (Chik, Rouse, Jaafar, Ismail, Azmi, Ghazali \& Ahmat, 2018).

Compared with other industry, academicians in higher education who have considerable autonomy in their work nature are expected to be held more accountable for their institute's performance. They are expected to identify problems, and initiate improvements in their performance before students' performances are adversely affected. In other words, their work's nature requires them to display proactive work behaviours that focus on initiating internal organisational change (Parker \& Collins, 2010). Furthermore, research on the topic of

eISSN: 2398-4287C 2021. The Authors. Published for AMER ABRA cE-Bs by e-International Publishing House, Ltd., UK. This is an open access article under the CC BYNC-ND license (http://creativecommons.org/licenses/by-nc-nd/4.0/). Peer-review under responsibility of AMER (Association of Malaysian Environment-Behaviour Researchers), ABRA (Association of Behavioural Researchers on Asians/Africans/Arabians) and cE-Bs (Centre for Environment-Behaviour Studies), Faculty of Architecture, Planning \& Surveying, Universiti Teknologi MARA, Malaysia.

DOI: https://doi.org/10.21834/ebpj.v6iSI4.2907 
employee's proactive work behaviour in Malaysia context is limited (Ling, Bandar, Alil, \& Muda, 2017) and specified in proactive career behaviour (Rahim \& Siti-Rohaida, 2016), proactive personality (Subramaniam,2015), proactive service behaviour (Hamzah, Othman \& Hassan, 2020) rather than proactive work behaviour. This motivates the present study to investigate the level of proactive work behaviour among the academicians in private universities in Malaysia.

\subsection{Literature Review}

Looking into the context of the study, academicians have high autonomy in their work nature and are held accountable for the performance of their institute. They are expected to identify problems, and initiate improvements in their performance before students' performances are adversely affected. Therefore, their work's nature requires them to display proactive work behaviours that focus on initiating internal organisational change (Parker \& Collins, 2010).

Proactive behaviour in prior research has referred to as a one-dimensional construct. However, in this study, it is best understood as a multi-dimensional construct, which includes self-initiated behaviours, such as taking charge, engaging in voice, initiating innovation, and problem prevention (El Baroudi, Fleisher, Khapova, Jansen, \& Richardson, 2017; Parker \& Collins, 2010). Taking charge is proactive actions by workers to bring about systemic change in the way work is carried out (Parker \& Collins, 2010). Voice addresses issues impacting one's working group and provides knowledge on such issues (Parker \& Collins, 2010). Initiating innovation is improving the internal organisation with novel solutions (Parker \& Collins, 2010). Problem prevention is self-directed and anticipatory behaviour taken to address recurring challenges and barriers in the workplace (Parker \& Collins, 2010). Proactive work behaviour was used for this study because these behaviours are focused on changing the internal organisational climate by enhancing work practises or influencing peers. The employee's proactivity level is influenced by various factors, including individual and situational factors (Bindl \& Parker, 2010). Many studies have explored individual factors such as proactive personality, but only a few have investigated proactive work behaviour's sociodemographic variables. (Bindl \& Parker, 2010; Ouyang, Lam, \& Wang, 2015). Socio-demographic factors are salient for workplace behaviour, but limited studies have studied it under primary objectives instead of using it as a control variable only (Chaudhary \& Rangnekar, 2017).

\subsection{Gender}

Concerning demographic variables and proactive work behaviour, inconsistent results were found (Bindl \& Parker, 2010). Many scholars argued that male is more proactive than female as they are generally more proactively participate in job search (Kanfer et al., 2001), networking behaviours (Claes \& Ruiz-Quintanilla, 1998), and voice up in the workplace (LePine \& Van Dyne, 1998). However, type and level of occupation are often confounded with gender and influence the proactivity level (Bindl \& Parker, 2010).

\subsection{Age}

Research findings have not always found consensus about the influence of age on proactive work behaviours. Some studies are demonstrating proactivity has no relationships with age (Warr \& Fay, 2001) whereas Jannsen and Van Yperen, (2004) noted that less proactivity for older workers. On the contrary, age was found to have a positive relationship with on-the-job proactivity (van Veldhoven \& Dorenbosch, 2008).

\subsection{Managerial position}

An employee with a higher hierarchical position can be assumed to exhibit a higher level of proactivity as their job resources and dedication level have been improved (Dikkers, Jansen, de Lange, Vinkenburg, \& Kooij, 2010). Mestdagh, Van Rompaey, Peremans, Meier, and Timmermans (2018) found that employee tends to be passive and dare not propose ideas due to hierarchical status. On the other hands, an employee with a higher hierarchical position has higher job autonomy and have greater latitude in taking the initiative than others (Glaser, 2016).

\subsection{Marital status}

When exploring the link between marital status and work performance and work effectiveness, the finding is demonstrating a positive association (Selmer, Suutari, \& Lauring, 2011). According to Ahituv and Lerman (2007), marriage might affect the work effort for both men and women, in turn, reflect on total hours worked. Shin and Park (2019) nevertheless found that employee marital status is a significant moderating factor in the relationship between workers' perceived materialistic benefits and their commitment to normative change.

\subsection{Level of Education}

In past studies, individuals' proactive behaviour at work was predicted well with knowledge and abilities (Kanfer et.al, 2001; Tornau \& Frese,2013). Similarly, LePine and Van Dyne (1998) found that education is positively linked to voice behaviour in the workplace. Higher education equips employees with knowledge and mental skills that help to develop proactivity. At the same time, employees ' confidence in speaking up and proposing creative solutions is also enhanced. (LePine \& Van Dyne, 1998).

\subsection{Work Tenure}


An employee with longer work tenure can be expected to display a higher level of proactivity as employees' job experience provides better knowledge of the job and the organisation. (Bindl \& Parker, 2010). With the profound knowledge about the organisation and its routines, employees can decide when to be proactive (Schmitt, Hartog, \& Belschak, 2016; Tornau \& Frese,2013).

\subsection{Methodology}

This study employs the non-probability sampling, purposive sampling method. Data are purposively collected from a readily available and accessible population who are academicians who work in private universities. In this study, the G-Power 3.0.10 statistical power analysis program is used to calculate the target sample size. Thus, run with an effect size of 0.15 (medium effect), an a of 0.05 , and a power of $0.95,160$ participants is generated as the minimum sample size for this study.

A total of the 13-item composite scale, measuring the four dimensions of proactive work behaviours was used in this study because of its emphasis on initiating internal organisational change (Parker \& Collins, 2010). The subscales of proactive work behaviours include taking charge ( 3 items), individual innovation ( 3 items), problem prevention ( 3 items), and voice ( 4 items). The respondents are asked to rate how often they exhibit proactive behaviour in their workplace based on a five-point Likert scale with an anchor from $1=$ 'Very infrequently/Never' to $5=$ ' very frequently/ Always'. Sample items from proactive behaviour (Parker \& Colins,2010) includes 'How frequently do you generate creative ideas?' and 'How frequently do you try to find the root cause of things that go wrong?'.

All the collected data were analysed using statistical software SPSS 23. Descriptive statistics were used to analyse the level of proactiveness of academicians in private universities. To analyse the differences between the overall proactive work behaviour of the academic staff based on their gender, managerial role, marital status, educational level, work tenure, and age, the independent sample t-test and one-way ANOVA, Post-hoc Tukey tests were executed.

\subsection{Findings and Discussion}

\subsection{Response rate}

As for the 1250 questionnaires distributed to 10 private universities in Malaysia, 302 questionnaires were replied. Out of the 302 , only 287 were found usable and 15 were discarded due to incompletion. Overall, 287 usable questionnaires were collected which yielded the response rate of $22.96 \%$.

\subsubsection{Demographic profile}

Among the total 287 respondents in the present study, most of them were female (63.1\%). This is a common phenomenon in higher education industry wherein the year 2017, 56 per cent of female academicians work in private universities in Malaysia (MOHE, 2017). This is also indicating the domination of female in the education line. In terms of analysis by age, the largest group of respondents was between 31 and 40 years old, with 47.4 per cent. Following the respondents' age 41-50 (31.7\%) and age 50 and above (11.5\%). Most of the academicians' Private universities in this study would consider to have their stable career foundation at their age 30s and above. However, it is still having a small number of relatively young ( $9.4 \%$ ) from the age group below 30 years old who may just complete their master's degree and be new to academia. Not surprisingly, majority of the respondents are married $(73.2 \%)$ and only a quarter of them single and others in divorce status. In general, 61 per cent of the respondents were awarded a Master Degree or equivalent. It was also noted that about 32.4 per cent of respondents received their $\mathrm{PhD}$ degree while there is still 6.6 per cent of respondents with a Bachelor degree. In terms of organisation tenure, the majority of experienced academicians (45.3\%) are attached to an existing institution for more than 8 years. This is followed by 6.1 to 8 years (18.8\%), 2 to 4 years (17.8\%), 4.1 to 6 years (12.5\%) and less than 2 years $(5.6 \%)$. The main reason for this may well be the respondents were from reputable Private universities. According to social identity theory, academicians will refrain from a turnover when they strongly identified with their institutions. Throughout the entire research, the respondents were responsive. Almost half of the respondents $(49.1 \%)$ held a managerial position in their institution such as dean, deputy deans, head of the programme, programme coordinator, programme director, head of the department, etc.

\subsubsection{Scale reliability and level of proactive work behaviour}

Reliability analysis had been carried out to check the consistency of the variable items. According to Ursachi, Horodnic, and Zait (2015), alpha coefficient (a) of 0.6-0.7 indicates an acceptable level of reliability, and 0.8 or greater a very good level. As shown in Table 1, the overall alpha coefficient of proactive work behaviour was found to be 0.867 and with an alpha coefficient of the four dimensions ranging from $0.667-0.840$, well above the threshold of 0.6 .

Table 1. Reliability Coefficient and Descriptive analysis of Proactive Work Behaviour

\begin{tabular}{lllll}
\hline Variables & Cronbach's Alpha & No of Items & Mean & SD \\
\hline Proactive Work Behaviour & 0.867 & 13 & 3.52 & 0.48 \\
Taking Charge & 0.667 & 3 & 3.72 & 0.54 \\
Problem Prevention & 0.686 & 3 & 3.58 & 0.57 \\
Individual Innovation & 0.756 & 3 & 3.52 & 0.65 \\
Voice & 0.840 & 4 & 3.25 & 0.71 \\
\hline
\end{tabular}


As depicted in Table 1, proactive work behaviour recorded a mean value of 3.52 out of 5.0 with a standard deviation of 0.48 , indicating that the respondents exhibit moderate proactiveness in their workplace. As can be seen, among the four activities which reflect the proactive work behaviour, voice recorded the lowest mean value of 3.25 whereby taking charge marked the highest mean value of 3.72 out of 5.0. This indicates that employee voice lacks the institution's lack of a proper mechanism to channel their voice or engage in employee silence instead of voice.

Considering gender differences, the results of t-test for proactive work behaviour were shown in Table 2. It was found that mean proactive work behaviour scores for male was higher than female and indicate significant differences $(p<0.05)$ in proactive work behaviour level of men $(M=3.61, S D=0.47)$ and female $(M=3.46, S D=0.47)$. The findings were in sync with most of the previous studies (Claes \& Ruiz-Quintanilla, 1998; Kanfer et al., 2001; LePine \& Van Dyne, 1998) where men are more proactive than women in terms of job search, networking and voice-over issues at the workplace.

Table 2. Independent T-test for Gender and Managerial position holder

\begin{tabular}{lccccc}
\hline Group & $\mathrm{n}=287$ & Mean & SD & $\mathrm{t}$ & Sig $-\mathrm{t}(2$ tails $)$ \\
\hline Gender & & & & & \\
Male & 106 & 3.61 & 0.47 & 2.603 & 0.010 \\
Female & 181 & 3.46 & 0.47 & & \\
Managerial Position & & & & -2.134 & 0.034 \\
Yes & 141 & 3.58 & 0.48 & & \\
No & 146 & 3.46 & 0.47 & &
\end{tabular}

Moreover, t-test result for a managerial position and proactive work behaviour were depicted in Table 2 . This revealed that academic staff holding the managerial position $(M=3.58, S D=0.48)$ are significantly more proactive than those who do not hold any managerial position in faculty and university ( $M=3.46, S D=0.47)$. This is in line with the findings of Dikkers, Jansen, de Lange, Vinkenburg and Kooij (2010) where proactivity of the employee has increased when levels of dedication and job resources have been improved. This could be because those academic staff in a managerial position have higher job autonomy and have greater latitude in taking the initiative than others (Glaser, 2016).

To examine whether age makes a difference in academicians' proactivity level in private universities, respondents were divided into four age groups: 30 and below, between 31-40, between 41-50, and above 51. One-way ANOVA was used for data analysis and the results are summarised in Table 3 . As can be seen, there were no significant differences in the level of proactivity of academicians with varying age groups in private universities. Simultaneously, the Tukey test is shown in Table 4 and confirms the lack of any significant differences in the different age groups. The findings contradicted most previous studies where age was significantly related to proactivity level either negatively (Jannsen \& Van Yperen, 2004) or positively (van Veldhoven \& Dorenbosch, 2008). Nevertheless, the finding was consistent with Warr and Fay (2001) results where there were no significant differences in proactivity level in different age groups. This probably suggests that all the academicians of all ages could be equally passionate into their job and take charge to improve teaching and learning effectiveness in the workplace.

Table 3. ANOVA test for Academic Staff's Age

\begin{tabular}{lllllll}
\hline Variable & Age Category & $\mathrm{n}=287$ & Mean & SD & $\mathrm{F}$ & Sig-F \\
\hline Proactive Work Behaviour & 30 and below & 27 & 3.44 & 0.35 & 2.272 & 0.080 \\
& $31-40$ & 136 & 3.49 & 0.48 & & \\
& $41-50$ & 91 & 3.51 & 0.48 & & \\
& Above 50 & 33 & 3.71 & 0.51 & & \\
\hline
\end{tabular}

Table 4. Post-hoc analysis for Academic Staff's Age -Tukey method

\begin{tabular}{|c|c|c|c|c|}
\hline Variable & Age Category & & Mean Difference & Sig. at $p<.05$ \\
\hline \multirow{11}{*}{ Proactive Work Behaviour } & 30 and below & $31-40$ & -0.053 & 0.952 \\
\hline & & $41-50$ & -0.067 & 0.916 \\
\hline & & Above 50 & -0.274 & 0.118 \\
\hline & $31-40$ & 30 and below & 0.053 & 0.952 \\
\hline & & $41-50$ & -0.015 & 0.996 \\
\hline & & Above 50 & -0.221 & 0.078 \\
\hline & $41-50$ & $\begin{array}{l}30 \text { and below } \\
31-40\end{array}$ & $\begin{array}{l}0.067 \\
0.015\end{array}$ & $\begin{array}{l}0.916 \\
0.996\end{array}$ \\
\hline & & Above 50 & -0.206 & 0.141 \\
\hline & Above 50 & 30 and below & 0.274 & 0.118 \\
\hline & & $31-40$ & 0.221 & 0.078 \\
\hline & & $41-50$ & 0.206 & 0.141 \\
\hline
\end{tabular}

In analysing the significant mean difference among the academician proactivity level based on the marital status, the one-way ANOVA results shown in Table 5 reveal a significant effect of marital status on proactivity level at 0.05 level of significance. Post-hoc Tukey test in Table 6 indicated that the mean proactivity score for married academicians $(M=3.55, S D=0.48)$ significantly differed from 
the single academicians $(M=3.39, S D=0.46)$. The results are in line with our expectation and previous studies (Ahituv \& Lerman, 2007; Selmer, Suutari, \& Lauring, 2011) where the married worker may have put in more effort into their work not only for their role in raising family income but also hoping to generate higher pay rate in the future.

Table 5. ANOVA test for Academic Staff's Marital Status

\begin{tabular}{lllllll}
\hline \multicolumn{7}{c}{ Table 5. ANOVA test for Academic Staff's Marital Status } \\
\hline Variable & Marital Status & $\mathrm{n}=287$ & Mean & SD & $\mathrm{F}$ & Sig-F \\
\hline Proactive Work Behaviour & Single & 70 & 3.39 & 0.46 & 4.009 & 0.019 \\
& Married & 210 & 3.55 & 0.48 & & \\
& Others & 7 & 3.73 & 0.43 & & \\
\hline
\end{tabular}

Table 6. Post-hoc analysis for Academic Staff's Marital Status - Tukey method

\begin{tabular}{|c|c|c|c|c|}
\hline Variable & Marital Status & & Mean Difference & Sig. at $p<.05$ \\
\hline \multirow[t]{5}{*}{ Proactive Work Behaviour } & Single & Married & $-0.166^{*}$ & 0.030 \\
\hline & & Others & -0.345 & 0.157 \\
\hline & Married & Single & $0.166^{*}$ & 0.030 \\
\hline & & Others & -0.178 & 0.586 \\
\hline & Others & Single & $\begin{array}{l}0.345 \\
0.178\end{array}$ & $\begin{array}{l}0.157 \\
0.586\end{array}$ \\
\hline
\end{tabular}

To test whether education level plays a role in determining proactivity levels among academicians in a private university, respondents were divided into three categories follow their highest education qualification i.e. bachelor degree, master degree and doctorate (PhD). The one-way ANOVA test findings as depicted in Table 7 revealed a significant difference in mean proactivity score among the academicians based upon different education levels at 0.05 level of significance. Post-hoc Tukey test from Table 8 indicated that the mean score for proactivity level at bachelor degree $(M=3.31, S D=0.36)$ was significantly different from those $P h D$ holders $(M=3.59$, $\mathrm{SD}=0.54$ ). However, the mean proactivity score for master degree holder did not significantly differ from bachelor degree holder and $\mathrm{PhD}$ holder. The results are in line with previous studies (Schmitt et al., 2016; Tornau \& Frese, 2013). An employee with higher-level education is normally equipped with knowledge and ability (e.g. problem-solving skills), which helps demonstrate change-oriented behaviour and more confidence to voice up (LePine \& Van Dyne, 1998).

Table 7. ANOVA test for Academic Staff's Highest Qualification

\begin{tabular}{lllllll}
\hline Variable & Highest Qualification & $\mathrm{n}=287$ & Mean & SD & $\mathrm{F}$ & Sig-F \\
\hline Proactive Work Behaviour & Bachelors degree or equivalent & 19 & 3.31 & 0.36 & 3.142 & 0.045 \\
& Masters degree or equivalent & 175 & 3.50 & 0.44 & & \\
& PhD or equivalent & 93 & 3.59 & 0.54 & & \\
\hline
\end{tabular}

\begin{tabular}{|c|c|c|c|c|}
\hline Variable & Highest Qualification & & Mean Difference & Siq. at $p<.05$ \\
\hline \multirow[t]{6}{*}{ Proactive Work Behaviour } & Bachelors degree or equivalent & Masters degree or equivalent & -0.185 & 0.238 \\
\hline & & $\mathrm{PhD}$ or equivalent & $-0.281^{*}$ & 0.049 \\
\hline & \multirow[t]{2}{*}{ Masters degree or equivalent } & $\begin{array}{l}\text { Bachelors degree } \\
\text { equivalent }\end{array}$ & 0.185 & 0.238 \\
\hline & & $\mathrm{PhD}$ or equivalent & -0.096 & 0.256 \\
\hline & \multirow[t]{2}{*}{$\mathrm{PhD}$ or equivalent } & $\begin{array}{l}\text { Bachelors degree } \\
\text { equivalent }\end{array}$ & $0.281^{*}$ & 0.049 \\
\hline & & Masters degree or equivalent & 0.096 & 0.256 \\
\hline
\end{tabular}

To examine whether work tenure makes a difference in academicians' proactivity level in private universities, respondents were divided into five groups: below 2 years, between $2-4$ years, between $4.1-6$ years, between $6.1-8$ years and above 8 years. The oneway ANOVA results for work tenure and proactivity level were in detailed in Table 8 , which show the insignificant difference between groups at $p>0.05$. Furthermore, Tukey's post hoc test also shows the same result where no significant differences were found in academicians' proactivity levels with varying tenure in the university. The result contradicted our expectation and past studies that have reported a positive relationship between work tenure and proactive work behaviour (Schmitt et al., 2016; Tornau \& Frese, 2013). However, in Tornau and Frese (2013) 's study, only tenure and voice show small significant relationship but found an insignificant relationship for other proactivity dimensions i.e. taking charge and personal initiative. Therefore, when the academicians under study demonstrated high level in taking charge and low level in voice, work tenure will not differ significantly in their proactivity level. In other 
words, the sense of mission as an academician always urge them to make constructive efforts on how work is performed regardless of how long they have been with the university.

Table 9. ANOVA test for Academic Staff's Organisation Tenure

\begin{tabular}{lllllll}
\hline Variable & Work Tenure & $\mathrm{n}=287$ & Mean & SD & $\mathrm{F}$ & Sig-F \\
\hline Proactive Work Behaviour & Below 2 years & 16 & 3.44 & 0.32 & 1.603 & 0.174 \\
& 2 to 4 years & 51 & 3.57 & 0.50 & & \\
& 4.1 to 6 years & 36 & 3.37 & 0.42 & & \\
& 6.1 to 8 years & 54 & 3.60 & 0.45 & & \\
& Above 8 years & 130 & 3.51 & 0.50 & & \\
\hline
\end{tabular}

Table 10. Post-hoc analysis for Academic Staff's Organisation Tenure -Tukey method

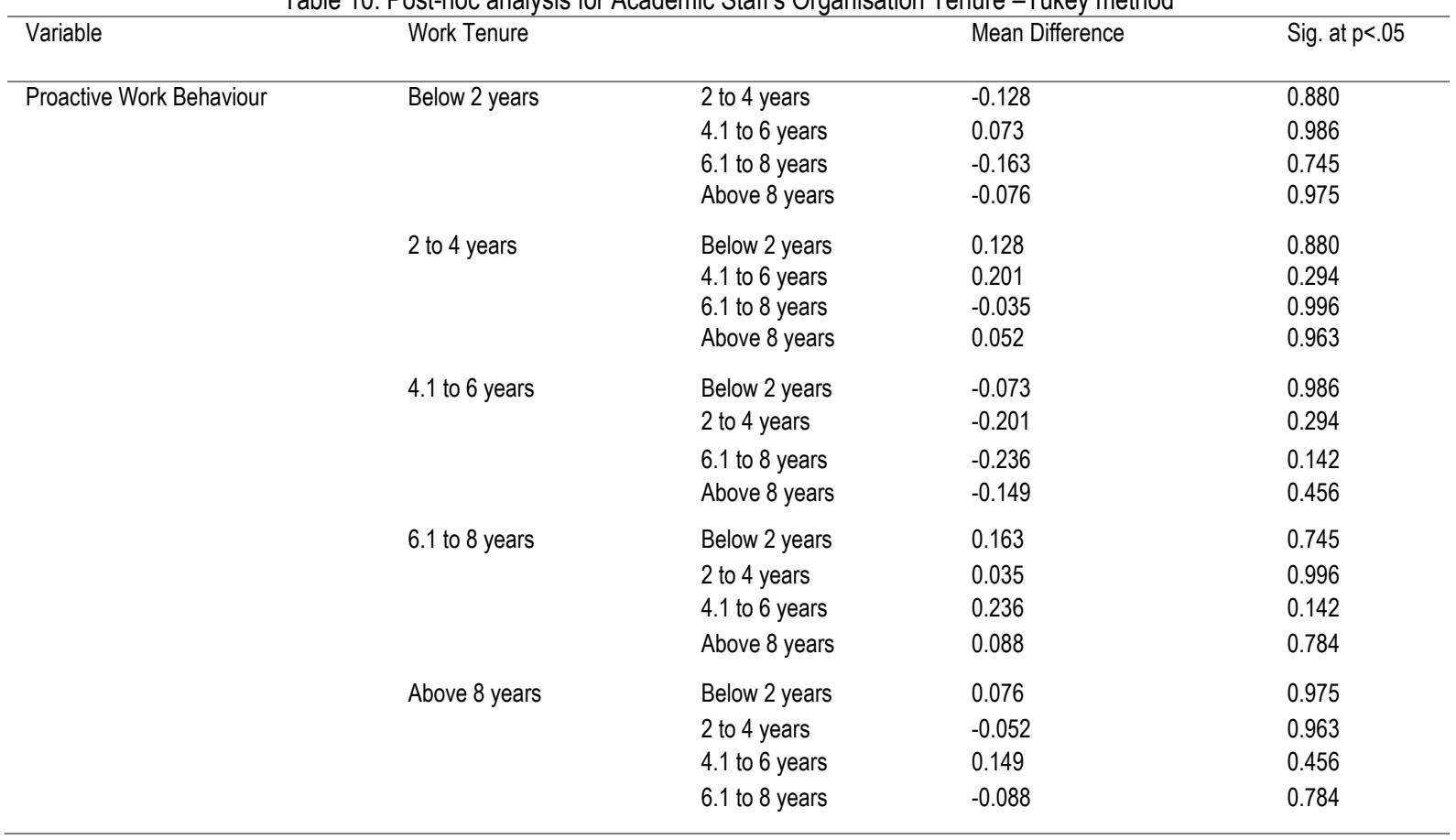

At a glance, the study depicts that academicians in private universities demonstrated moderate proactivity level where taking charge was their main role display. Regarding the socio-demographic variables, namely gender, marital status, education level, and managerial position have shown significant differences in proactivity level among academicians, whereby age and work tenure did not differ significantly with proactivity level.

\subsection{Conclusion and recommendations}

This study's findings provide several useful implications for management on how to improve the proactivity level among academicians in a private university. Different approaches need to adapt while assigning work tasks or initiatives, taking into account gender, marital status, educational differences and managerial position. For instance, management can assign more challenging role to male staff compare to female staff, especially married male staff. They have a higher sense of family obligation and are willing to spend more time in their works to provide financial support for their family (Choong, Keh, Tan, \& Tan, 2013). Furthermore, since academician who holds a managerial position in faculty or university tends to be more proactive, succession planning should have in place to ensure capable academicians have the equal opportunity to be appointed for the position. This may promote diversity of thought to drive innovation and creativity in the university. Lastly, management should encourage and support the academicians to further study in doctorate. Higher education level will generate higher abilities that help individuals identify ineffective procedures and anticipate future organisational needs (Tornau \& Frese, 2013).

Every study has its limitations. This study's main limitation is the target respondent, which only focuses on academic staff in Malaysian private universities. Thus, the findings did not apply to public universities and colleges due to different work cultures, environments, and policies. Apart from that, only limited demographic factors were investigated in this study. Personal factors such as Big-5 personality and self-efficacy which may have a direct impact on the proactivity level of employee. Further studies may have carried out to include other variables which remained unmeasured. 


\section{References}

Ahituv, A., \& Lerman, R. I. (2007). How do marital status, work effort, and wage rates interact?. Demography, 44(3), 623-647.

Bindl, U. K., \& Parker, S. K. (2010). Proactive work behaviour: Forward-thinking and change-oriented action in organisations. APA Handbook of Industrial and Organizational Psychology, 2(2010), 567-598.

Chaudhary, R., \& Rangnekar, S. (2017). Socio-demographic Factors, Contextual Factors, and Work Engagement: Evidence from India. Emerging Economy Studies, 3(1), $1-18$

Chik, E. R. E., Rouse, F. M., Jaafar, C. R. C., Ismail, M. I., Azmi, N. A., Ghazali, M. M., \& Ahmat, M. A. (2018). Report on the Contribution of Universities and Research Institutions in Scientific Development of Islamic Countries: The Case of Malaysia. Islamic World Science Citation Center (ISC) Newsletter.

Choong, Y.-O., Keh, C.-G., Tan, Y.-T., \& Tan, C.-E. (2013). Impacts of Demographic Antecedents toward Turnover Intention amongst Academic Staff in Malaysian Private Universities. Australian Journal of Basic and Applied Sciences, 7(6), 46-54.

Claes, R., \& Ruiz-Quintanilla, S. (1998). Influences of early career experiences, occupational group, and national culture on proactive career behaviour. Journal of Vocational Behavior, 52, 357-378.

Dikkers, J. S. E., Jansen, P. G. W., de Lange, A. H., Vinkenburg, C. J., \& Kooij, D. (2010). Proactivity, job characteristics, and engagement: A longitudinal study. Career Development International, 15(1), 59-77.

El Baroudi, S., Fleisher, C., Khapova, S. N., Jansen, P., \& Richardson, J. (2017). Ambition at work and career satisfaction. Career Development International, 22(1), 87102

Glaser, L. (2016). Managing The Risks Of Proactivity : A Multilevel Study Of Initiative And Performance In The Middle Management Context, Academy of Management Journal, 59(4), 1339-1360.

Hamzah, M. I., Othman, A. K., \& Hassan, F. (2020). Elucidating salespeople's market orientation, proactive service behaviour and organizational culture in the B2B banking sector: a Malaysian perspective. International Journal of Bank Marketing, 38(5), 1033-1057.

Hashim, R. (2012). Muslim private higher educational institutions in Malaysia: issues and challenges. Islam and Civilisational Renewal, 3(3), 474-488.

Jannsen, O., \& Van Yperen, N. W. (2004). Employees' goal orientations, the quality of leader-member exchange, and the outcomes of job performance and job satisfaction. Academy of Management Journal, 47(3), 368-384.

Kanfer, R., Wanberg, C. R., \& Kantrowitz, T. M. (2001). Job search and employment: A personality-motivational analysis and meta-analytic review. Journal of Applied Psychology, 86(5), 837-855

LePine, J. A, \& Van Dyne, L. (1998). Predicting voice behaviour in workgroups. Journal of Applied Psychology, 83(6), 853-868.

Ling, N. P., Bandar, N. F. A., Alil, F. A. H., \& Muda, A. L. (2017). Proactive behaviour as a mediator in the relationship between quality of work-life and career success International Journal of Business and Society, 18(S4), 701-709.

Mestdagh, E., Van Rompaey, B., Peremans, L., Meier, K., \& Timmermans, O. (2018). Proactive behaviour in midwifery: A qualitative overview from midwifery student's perspective. Nurse education in practice, $31,1-6$.

Ouyang, K., Lam, W., \& Wang, W. (2015). Roles of gender and identification of abusive supervision and proactive behaviour. Asia Pacific Journal of Management, 671691.

Parker, S. K., \& Collins, C. G. (2010). Taking stock: Integrating and differentiating multiple proactive behaviours. Journal of Management, 36(3), 633-662.

Rahim, N. B., \& Siti-Rohaida, M. Z. (2016). The Influence of Proactive Career Behaviours on Psychological Well-being among Malaysian Engineers. Global Business Review, 17(3_suppl), 30S-44S.

Schmitt, A., Hartog, D. N. Den, \& Belschak, F. D. (2016). Transformational leadership and proactive work behaviour : A moderated mediation model including work engagement and job strain, Journal of occupational and organisational psychology, 89(3), 588-610.

Selmer, J., Suutari, V., \& Lauring, J. (2011). Marital status and work outcomes of self-initiated expatriates. Cross-Cultural Management: An International Journal, 18(2), 198-213.

Shin, J., \& Park, J. (2019). The interactional effect between employees' perceived materialistic rewards and marital status on attitudinal and behavioural outcomes: An empirical investigation. Current Psychology, 1-10.

Subramaniam, H. (2015). The Influence Of Human Resource Management Practices And Proactive Personality On Job Performance Among Commercial Bank Employees. Universiti Utara Malaysia.

Tornau, K., \& Frese, M. (2013). Construct Clean-Up in Proactivity Research: A Meta-Analysis on the Nomological Net of Work-Related Proactivity Concepts and their Incremental Validities. Applied Psychology, 62(1), 44-96.

Ursachi, G., Horodnic, I. A., \& Zait, A. (2015). How reliable are measurement scales? External factors with indirect influence on reliability estimators. Procedia Economics and Finance, 20(15), 679-686.

Van Veldhoven, M., \& Dorenbosch, L. (2008). Age, proactivity and career development. Career Development International, 13(2), 112-131. 
Cheah, C.S., et.al. / CSSR2019, Parkroyal Penang Resort, Batu Ferringhi, Pulau Pinang, Malaysia, 04-05 Dec 2019 / E-BPJ, 6(SI4) Jul 2021 (pp. 95-102)

Warr, P., \& Fay, D. (2001). Age and personal initiative at work. European Journal of Work and Organizational Psychology, 10, 343-353 